\title{
Slovenska mladinska proza med posnemanjem dejanskega in ustvarjanjem možnih svetov
}

Barbara Zorman

Univerza na Primorskem, Pedagoška fakulteta, Cankarjeva ulica 5, 6000 Koper https://orcid.org/0000-0003-3498-6958

barbara.zorman@upr.si

V razpravi najprej predstavim razlikovanje med realistično in fantastično mladinsko prozo, ki izhaja iz načinov referiranja na zunajbesedilni svet. Realizem pripoved podaja $v$ skladu z uveljavljenimi predstavami o tem, kar je v stvarnem oziroma dejanskem svetu možno in verjetno, fantastika pa te predstave z ustvarjanjem alternativnih svetov prevprašuje. Dokazati želim, da večina mladinskih proznih del ne soupada zgolj z realistično oziroma fantastično reprezentacijo, temveč oba principa prepleta. V mladinski realistični prozi so igra, domišljija, upor, humor in nonsens temeljna načela, skozi katera se odrasli avtor vživlja v mladoletni lik in tako nasprotuje poskusom odrasle avtoritarne perspektive, da bi se vzpostavila kot obče veljavna resnica o svetu. Tudi fantastične literature ni mogoče ustvarjati ali sprejemati brez referenc na dejanski svet. Zato predlagam, da se dvojica realistično/fantastično razpre v spekter, ta pa se oblikuje s pomočjo koncepta modalno pogojene resničnosti oziroma dejanskega ter možnih in neverjetnih svetov. Spekter se razpira med dvema skrajnima poloma: verističnim referiranjem na zunajbesedilno stvarnost (temu so blizu avtobiografije, spominska in zgodovinska proza) ter ubesedovanjem možnih/neverjetnih svetov, likov, dogodkov na drugem polu, čemur so blizu pravljice, fantastična proza, nonsens.

Ključne besede: slovenska književnost / mladinska književnost / realizem / fantastika / fantazijska literatura / teorija možnih svetov

\section{Realistično/fantastično $\mathrm{v}$ mladinskem pripovedništvu}

Ločnica, ki slovensko mladinsko prozo deli na realistično in nerealistično, pogojuje znanstvene raziskave sodobne in pretekle slovenske mladinske proze, žanrske klasifikacije in književno vzgojo. V slovenskem prostoru se je razločevanje prvič izrazito vzpostavilo v študiji Marjane Kobe Pogledi na mladinsko književnost. Pozneje so klasifikacijo znotraj resničnostne in neresničnostne literature razvijali še Igor Saksida, Dragica Haramija, Milena Mileva Blažić in drugi. Marjana Kobe realistično 
mladinsko prozo definira $\mathrm{z}$ upovedovanjem socialne resničnosti, ki se giblje v okvirih izkustveno preverljivega sveta, pri čemer se teme oziroma protagonisti te proze največkrat vežejo na doživljajski svet otroka oziroma mladostnika (Kober, »Trije« 89), fantastično prozo pa kot dvoplastno pripovednost, kjer se podajanje dogajanja ter prostorsko-časovnih razsežnosti, ki se nanašajo na verodostojne podatke o zunajbesedilnem svetu, izmenjuje $\mathrm{z}$ elementi fantastičnega dogajanja ter predstavitvami prostorskih in časovnih kategorij, ki presegajo racionalno dojemanje stvarnega sveta (Kobe, Pogledi 109-164). Predstavljeni binarizem gradi na nasprotjih: racionalno/iracionalno, verodostojno/neverodostojno, preverljivo/nepreverljivo, realistično/fantastično, posnemanje/izmišljanje. Resničnostna in neresničnostna literatura tako opredeljujeta druga drugo s pomočjo negacije, pri tem pa pedagogi in didaktiki realizmu pogosto pripisujejo višjo spoznavno vrednost od fantastike, ki naj bi otrokom rabila le za beg od reševanja stvarnih problemov (glej npr. Nikolajeva, Reading 28). V pričujočem tekstu bom izhajala iz dveh premis. Prvo je izpostavila Kathryn Hume v delu Fantasy and Mimesis (1984), in sicer, da sta fantastično preoblikovanje in realistično posnemanje sveta dva temeljna impulza umetniškega ustvarjanja in da je torej vsako literarno delo preplet realističnih in fantastičnih prvin. Maria Nikolajeva pa $\mathrm{v}$ Reading for Learning (2014) trdi, da ima literarno predstavljanje, ki z gradnjo alternativnih svetov izziva bralčeve kognitivne sheme, enako ali morda višjo spoznavno vrednost od realizma (44).

\section{Fantastično v mladinskem pripovedništvu}

Da je fantastične elemente pravzaprav težko dokončno razmejiti od realističnih, nakazuje že študija Tzvetana Todorova Introduction à la littérature fantastique (1970), na katero se je pri svoji opredelitvi fantastičnega opirala Marjana Kobe. Todorov fantastično v literaturi definira kot občutek negotovosti, omahovanja, ki se ob soočenju $s$ pojavi nadnaravnih razsežnosti polasti glavnega junaka in z njim vred bralca, saj ne poznata drugih zakonitosti, kot so zakonitosti njunega resničnega sveta; fantastično zaobjema čas te negotovosti (Todorov, The Fantastic 31). Ko si lik oziroma bralec nenavadni dogodek razloži z razumsko razlago - denimo, da so na spremembo v subjektivnosti vplivale norost, zastrupitev ali sanje, se kategorija fantastičnega izniči v prid nenavadnega (l'étrange) (46). Če pa pripoved spodbuja iracionalno razlago dogajanja oziroma dopušča obstoj nadnaravnega, potem fantastično postane čudežno (le merveilleux). Kar danes v mladinski literaturi pojmujemo 
kot fantastično plast neresničnostne proze, v teoriji Todorova ustreza kategoriji čudežnega. To se po Todorovu deli na štiri podvrste. Prva vrsta je hiperbolično čudežno in izvira iz pripovednega pretiravanja, torej je objekt čudežen zgolj zato, ker je v zgodbi predstavljen v mnogo večjih dimenzijah, kot jih je vajen bralec, na primer v Sindbadovih dogodivščinah so kače tako velike, da lahko požrejo slone. Vendar pa je to, kot zapiše Todorov, lahko le poetični ali alegorični način izražanja, ki ne oslabi racionalnega tona besedila (55). Druga vrsta je eksotično čudežno in izvira iz geografske tujosti. V Sindbadovih potovanjih je tako na primer predstavljen fantastični velikanski ptič, ki naj bi obstajal $\mathrm{v}$ bralcu oddaljenih in neznanih pokrajinah. Tretja podvrsta, instrumentalno čudežno, se ustvarja s pomočjo nenavadnih predmetov, kot je na primer leteča preproga ali jabolko, ki ozdravi vse bolezni, obenem pa antibiotiki ali helikopter ne sodijo $\mathrm{v}$ domeno instrumentalnega čudežnega, saj so produkt človeškega razuma in veščine, ne pa magije oziroma komunikacije z nadnaravnimi silami. Četrta podvrsta, tj. znanstveno magično, ki je blizu znanstveni fantastiki, razlaga nadnaravno v okviru racionalnega, vendar z upoštevanjem principov oziroma zakonov, ki jih sodobna znanost ne priznava (56).

Podobno kot Tzvetan Todorov tudi Mark J. P. Wolf predstavi štiri kategorije invencije, tj. odklonov, $v$ katerih se ustvarja fantazijska fikcija $s$ preoblikovanjem elementov bralcu znanega, empirično preverljivega sveta. Ravni imenuje: nominalna (znani pojavi v fantazijskem literarnem svetu dobijo nova imena), kulturna (fantazijski svet ponudi novo različico kulture, ki lahko kombinira eno ali več elementov kultur iz dejanskega sveta; invencija je prisotna $\mathrm{v}$ prikazu politične ureditve, družbenih praks, artefaktov itd.), naravna (spremenjena je pokrajina, flora in favna, bitja in rase ali pa kar celoten ekosistem) ter ontološka na tej ravni gre za ontološke odklone od znanih parametrov obstoja, npr. od fizičnih ter časovno-prostorskih zakonov (Wolf 35-36). Catherine Butler predstavi pet načinov, s katerimi Joanne K. Rowling realni svet preobrazi v fantazijski: uresničenje (fantazijska bitja iz mitov/pravljic, npr. kentavri, se uresničijo $\mathrm{v}$ zgodbenem dogajanju), nadomeščanje (pojav iz magičnega sveta izraža strukturno korespondenco s pojavom iz dejanskega sveta, npr. quiddich ali časopis The Daily Prophet), pretiravanje (znan pojav tekst prikaže hiperbolično, npr. lahko izbereš med bomboni vsakega okusa), animacija (oživljanje neživega, npr. govoreče slike) in starinjenje, kjer pripoved uporablja starinski prostor, dikcijo, politično organizacijo itd. (Butler 233). Vse navedene kategorije čudežnega izhajajo iz principa, ki neresnično ustvari s preoblikovanjem resničnega. Estetsko preoblikovanje stvarnosti pa Roman Jakobson v 
eseju »On Realism in Art«, h kateremu se vrnemo v nadaljevanju, vzpostavlja kot temelj vsakega umetniškega upodabljanja. Fantastično se po Todorovu manifestira zlasti v subjektivni pripovedi, preko prvoosebnega pripovedovalca, ki poudari ambivalentnost pomena kot dominantno lastnost fantastičnega. Kot tipična primera "čistega fantastičnega" navaja Todorov Gogoljevo zgodbo Plašč in Lewisov roman Menih (Todorov, The Fantastic 72, 126). Pri Todorovu torej fantastično traja toliko kot negotovost, $\mathrm{v}$ kateri bralec, ki bere o domnevno nadnaravnem dogodku, okleva med vero in nejevero $\mathrm{v}$ iracionalni, nadnaravni izvor nekega pojava. V mladinski književnosti pa je fantastično opredeljeno kot prisotnost nemogočega $\mathrm{v}$ ali ob dogajanju, ki ne krši zakonov nujnosti ali verjetnosti.

\section{Realistično v mladinskem pripovedništvu}

Znanstvenice, ki obravnavajo realizem v slovenski mladinski prozi, tega ločujejo od realizma v smislu literarnega obdobja (glej npr. Kobe in Haramija). Hkrati pa mladinski realizem, skupaj s številnimi drugimi različicami realizmov (z izjemo, nemara, magičnega realizma) druži prizadevanje po objektivnem odslikavanju realnosti. Vero v literarno oziroma jezikovno zmožnost objektivnega posnemanja stvarnosti so sicer v 20. stoletju omajale lingvistika, zlasti de Saussurovo dognanje o arbitrarnosti jezika, psihoanaliza in fenomenologija (glej Virk). Eksplicitno pa je realizem kot reprezentacijo, ki ne podaja objektivnega, temveč relativni, od percepcije ustvarjalca/prejemnika odvisni prikaz stvarnosti, izpostavil Roman Jakobson v že omenjenem, leta 1921 prvič objavljenem eseju »On Realism in Art«, kjer zapiše, da je v dotlej uporabljenem terminu realizem »objektivna in nesporna veljavnost pripisana individualni, osebni lokalni perspektivi« (20). Spregledana relativnost oziroma kulturna pogojenost realističnega predstavljanja je postala močan argument v diskurzu postkolonializma, npr. v vplivnem eseju Homija Bhabhe »Representation and the Postcolonial Text« (1984), ki opredeli historicizem in realizem kot imperialistično fikcijo, ki zanika lastno skonstruiranost oziroma fikcijskost (glej Dalley). Nikolajeva hegemonični diskurz kolonialnega realizma primerja z aetonormativnostjo (odraslo normativnostjo), ki obvladuje mladinsko književnost (Nikolajeva, Power 20; Nikolajeva, Reading 33). Aetonormativnosti ustreza večina del mladinske proze, ki je konec 19. in v začetku 20. stoletja uporabljala realistične pripovedne strategije, ne zavoljo želje po dokumentiranju stvarnosti, temveč kot krinko za naturalizacijo 
ideologije. Marjana Kobe ugotavlja, da »slovenske povestice«, nastale po zgledu nemškega razsvetljenskega vzorca, »realizirajo vse tri tipe moralične zgledne zgodbe: [...] zgled za posnemanje, svarilen zgled ter kombinacijo zgleda in svarila $\mathrm{v}$ kratki zgodbi z dvema kontrastnima otroškima likoma« (Kobe, "Otroški« 9). V slovenski mladinski prozi 20. stoletja se didaktična funkcija vse bolj umika estetski, znotraj te pa se kot ključna metoda pisanja za mladino vzpostavlja vživljanje v otroško/mladostniško perspektivo, tj. pozicija, ki omogoči pisatelju začasen izstop iz odrasle avtoritarne perspektive (Saksida, "Opredelitve«). Vživljanje se $\mathrm{v}$ mladinski realistični prozi uresničuje bodisi z uporabo humorja (zlasti hiperbol) ali pa kot subjektivna prvoosebna pripoved, znotraj katere je poudarjeno modalno pogojevanje stvarnosti, tj. barvanje sveta v skladu z željami, strahovi, fantazijami, predstavami, stališči fokalizatorja, vse to pa subvertira možnost predstavljanja dejanskega sveta kot enotnega in stvarnega. Predstave o resničnosti se tako lahko razgalijo kot hipoteze in izmišljije (glej Juvan, »Fikcija« 9). Mladinske pripovedi, ki so postavljene $\mathrm{v}$ šolsko ali športno okolje, pogosto tematizirajo upiranje mladih, ki se manifestira preko humorne subverzije. Ta je sorodna karnevalski inverziji Mihaila M. Bahtina. Namen karnevalskega dogajanja je prevpraševanje obstoječega družbenega reda in začasna sprostitev od hierarhičnih razmerij. Oglejmo si ta princip v primerih iz Preglovega romana Geniji v kratkih hlačah:

A jaz?« je vprašal Pipi in skušal zbasati v usta balonček iz žvečilnega gumija, ki ga je ravnokar napravil.

»Ti, ja. Pridi sem!« Pipi se je negotov napotil proti človeku v temni obleki, ki ga je precej namrščen vabil k sebi. Mož je imel črtasto kravato, skodrane sive lase, bil je visok in odločen.

"Poslušaj, mulc, « je začel, »lahko, da si prišel iz džungle, lahko, da si prišel iz stolpnice. Ampak, čisto vseeno je, od kod si prišel. Važno je, kam si prišel. In prišel si v šolo. Tu, prvič ne žvečimo žvečilnega gumija, drugič ne rinemo rok do ramen v žepe in tretjič, ... hm, tretjič, ... oho, kdaj si bil zadnjič pri frizerju?« »Hm,« je malo zmedeno odgovoril Pipi.

Pipi se je zamislil. Od daleč je bilo videti, da mora iz takega razmišljanja pasti vsaj formula za heksaklorcikloheksan ali pa odgovor na večno vprašanje o tem, če je bila prej kokoš ali jajce. Od blizu je bilo videti, da se Pipi zafrkava. Sivi kodri so poskočili.

„Ne brskaj po glavi, če v njej nič nimaš! Ne zanima me, kdaj si bil zadnjič, povem ti pa, da boš naslednjič pri frizerju danes popoldne, sicer bo joj.« Mož je odvihral, Pipi pa je začudeno gledal okrog sebe. Neka sivoprosojna prekla dekliškega spola, ki bi jo lahko uporabljali za lestev in jo prislanjali ob Eifflov stolp, če bi gorelo v sedemindvajsetem nadstropju, mu je rekla, da se je pravkar srečal $\mathrm{z}$ novim ravnateljem šole, $\mathrm{v}$ katero je danes prvič po počitnicah spet vstopil (5). 
Kot kaže navedeni primer, humorna proza prilagaja atribute dejanskega sveta načelom smeha, igre in ugodja, poudarja zabavna neskladja in izjeme in skratka bralca zabava s svojimi odkloni od vsakdanjega. Pri humorju gre večkrat za igrivo preoblikovanjem kategorij, logičnih in lingvističnih pravil. Temu v Košarkar naj bo (Primož Suhodolčan) dosledno sledi jezikovni inovator Smotlak, ki je nekakšen notranji komentator dogajanja. Tudi tretjeosebni pripovedovalec zelo pogosto $s$ hiperbolami odstopa od zakonov nujnega in verjetnega: "To je zgodba o fantu, ki je bil tako velik, da bi lahko žirafam kravate zavezoval, ki je bil tako suh, da je sonce kar skozenj sijalo, ki je pojedel vse, kar so si mu prinesel na krožnik, potem pa še krožnik.« (5) Humorna proza $v$ pripoved vnaša elemente iracionalnega, fantastičnega, nonsensnega, neverjetnega, kar potrjuje domnevo, da se $\mathrm{v}$ večini proznih besedil prepletajo elementi posnemanja stvarnega sveta in izmišljanja neverjetnih svetov/pripovedi. Do katere mere sodijo humorna pretiravanja in nonsensi, ki mladim sladijo bralne napore, v zunanje-formalno, slogovno plast, ločeno od motivno-tematske plasti literarnih del? Kdaj pa pretiravanje in potujevanje stvarnosti motiviko odpelje od realizma proti fantastiki? Kako določiti mejo? Roman Košarkar naj bo, denimo, režiser njegove filmske priredbe, Boris Petković, opisuje kot "[f]antazijski, nadrealni svet, v katerem kraljuje otroška domišljija« (nav. po M. K.), kar je v nasprotju z njegovo opredelitvijo $\mathrm{v}$ domeni realistične proze. Mladinsko prozo Frana Milčinskega, Slavka Pregla, Polonce Kovač, Primoža Suhodolčana znanstveniki navadno umeščajo v domeno realizma, ker se pripovedni čas, prostor in večina dogajanja gibljejo znotraj konvencij verjetnosti in nujnosti (glej Haramija, "Pregled«; Saksida, "Mladinska«). Vendar pa je slogovna plast teh besedil močno prežeta $s$ humorjem in nonsensom, ki družbeno veljavne predstave resničnosti potujuje. Zato lahko zaključimo, da tudi v številna prozna dela, ki predstavljajo vsakdanje življenje otrok in najstnikov, humor in nonsens vnašata elemente neverjetnega, tj. fantastičnega.

Podobno v številnih primerih mladinske proze, označenih kot realističnih, literarnemu "igranju dejanskosti in sidranju v stvarnosti« (Juvan, "Fikcija« 9) nasprotuje velika količina nenavadnih, napetih in zabavnih dogodivščin. Te so zlasti pogoste $\mathrm{v}$ avanturistični prozi, ki jo Dragica Haramija označuje z »bogastvom dejanj, napetim prikazovanjem dogodkov, nizanjem nevarnih situacij in njihovo razrešitvijo [...], opisovanjem geografsko, zgodovinsko in socialno oddaljenih okolij in književnim junakom z nadpovprečnimi lastnostmi« (Haramija, "Slovenska« 6-8). S temi značilnostmi se avanturistična proza navezuje na pravljico, srednjeveško romanco in robinzonado 
ali vestern. Med sodobno slovensko zgodovinsko-avanturistično mladinsko prozo v zadnjih letih izstopa cikel Igorja Karlovška Ognjeno pleme. Tega spričo obsežnih fantastičnih pasusov težko opredelimo kot zgolj realistično pripoved. A tudi v starejših avanturističnih, športnih in detektivskih pripovedih, ki dogajanja ne umeščajo ne $\mathrm{v}$ nadrealno niti v eksotično preteklost oziroma geografijo, zadovoljevanje bralčeve potrebe po zabavi in akciji vodi pripoved v umetelno zgoščanje dogajanja, nizanje nepričakovanih preobratov, naključij in težko verjetnih srečnih izidov.

V zadnjih letih je na Slovenskem opazen porast problemskih besedil, ki so namenjena bralcem vseh starosti (Višček 69). V teh se poleg personalne pripovedi kot najpogostejši vzorec uveljavlja prvoosebna pripoved. Resničnost tu v veliki meri obstaja subjektivno, tj. zgolj $\mathrm{v}$ zavesti fokalizatorja/pripovedovalca, ne pa izven nje. V knjigi Polonce Kovač Kaja in njena družina nasveti in spodbude, ki jih Kaji posredujeta kristal in zeleni zajec, obstajajo samo v zavesti protagonistke Kaje in ne $\mathrm{v}$ dejanskem zgodbenem svetu. Njena mama na primer teh sporočil ne zaznava. Poleg tega je z avtoritarno pozicijo, ki se predstavlja kot objektivna reprezentacija stvarnosti, subjektivna pripoved otroka/ odraščajočega pogosto $\mathrm{v}$ konfliktu. Zanimivo soočenje med dvema percepcijama resničnosti je izkazano v naslovni črtici zbirke Solzice. Avtoritarna pozicija očeta, ki na prostor globače, imenovane Pekel, gleda predvsem utilitarno, je v konfliktu s percepcijo fokalizatorja. Ta $\mathrm{v}$ prostor globače projicira svoje vizije strašnega prostora, ki si jih je, nemara nehote, prisvojil iz krščanskega imaginarija. Možnost obstoja pekla v neposredni bližini, v katero proti svoji volji verjame fokalizator, tako v Solzicah vdira v realni prostor kmečkega življenja. Konflikt v očetovih in pripovedovalčevih predstavah o prostoru v pripoved naša ambivalentnost, negotovost, ta pa je blizu omahovanju med racionalno in iracionalno razlago pripovednih elementov, ki je po Todorovu vnaša značilnost fantastičnega. Ime mi je Damjan Suzane Tratnik podobno kot Solzice zoperstavlja resničnost očeta nasproti resničnosti mladega pripovedovalca. Tu je avtoritarna očetova (in z njo večinska) interpretacija protagonistove spolne identitete $\mathrm{v}$ nerazrešljivem konfliktu s protagonistovo samopercepcijo, doseženo tudi s pomočjo psihoterapevtske pripovedi. Tak način reprezentacije se ujema s predstavo o resničnosti kot indeksalnemu pojmu, ki je »odvisen od subjektovega izkustvenega sveta in urejen okrog opazovalne točke jaz-tukaj-zdaj» (Juvan, "Fikcija» 9). Podobno strukturo, kjer je resničnost prikazana kot mozaik različnih osebnih resnic, videnj, diskurzov, najdemo $\mathrm{v}$ številnih sodobnih problemskih besedilih, med najsodobnejšimi denimo $\mathrm{v}$ pripovedih $T u$ 
blizu živi deklica (Ida Mlakar Črnič), Kot noč in dan, Vsak s svojega planeta (Cvetka Sokolov) idr. Sodobni realizem mladinske problemske proze je torej nemara še najbližje psihološkemu tipu realizma, ki se osredinja na misli in motivacije različnih likov. Karen Coats meni, da mladinska proza, ki poskuša verodostojno posnemati subjektivnost (čustva, misli, želje itd.) fiktivne osebe, zlasti ko je ta od bralca kulturno ali zgodovinsko oddaljena, ponuja najučinkovitejši način za "vstop v glavo« sočloveka oziroma za razvijanje empatije ter teorije uma (Coats 333). Subjektivno posredovana pripoved torej pogosto predstavlja modalno pogojeno realnost; v projicirana čustva, misli, želje, sanje, strahove, predstave likov. Ilustracijo pripovedi, ki jo bolj kot opisi dejanskega stanja pogojujejo podobe, ki jih generirajo želje, predstave in fantazije protagonistke, najdemo na prvih straneh knjige Nataše Konc Lorenzutti Nisem smrklja.

\begin{tabular}{|l|l|l|}
\hline $\begin{array}{l}\text { Izjave o dejanskem svetu } \\
\text { pripovedi }\end{array}$ & $\begin{array}{l}\text { Predstave o uresničljivih } \\
\text { dogodkih }\end{array}$ & $\begin{array}{l}\text { Predstave o } \\
\text { neuresničenih in } \\
\text { neuresničljivih dogodkih }\end{array}$ \\
\hline & $\begin{array}{l}\text { Vadim, kako se bom } \\
\text { predstavila, ko bom } \\
\text { odrasla. Dala bom člo- } \\
\text { veku desno roko in rekla: } \\
\text { "sem Polona Bukovec. } \\
\text { Me veseli.» }\end{array}$ & \\
\hline $\begin{array}{l}\text { Čisto zadovoljna sem s } \\
\text { svojim imenom }\end{array}$ & & $\begin{array}{l}\text { Če bi se mojim staršem } \\
\text { namesto mene rodil fant, } \\
\text { bi bil Nikolaj. Miklavž } \\
\text { Bukovec, pobriši tablo, } \\
\text { bi rekli v šoli, kar je } \\
\text { skoraj tako, kot da bi me } \\
\text { klicali dedek Mraz. }\end{array}$ \\
\hline $\begin{array}{l}\text { Za rojstni dan sem si želela } \\
\text { sestro, ampak sta tata in } \\
\text { mama rekla, da se otrok } \\
\text { ne da kar tako naročiti, } \\
\text { zato sem dobila uhane. Z } \\
\text { mamo sva šli k zlatarju. }\end{array}$ & $\begin{array}{l}\text { Gledala sem v stekleno } \\
\text { omarico in si za trenutek } \\
\text { predstavljala, da so v njej } \\
\text { žive zlate punčke. Izbrala } \\
\text { bi si najlepšo in vzeli bi jo } \\
\text { domov. }\end{array}$ \\
\hline
\end{tabular}

Izpostavljam torej vprašanje, ali binarizma realistična/fantastična literatura ne bi bilo uporabno razpreti v spekter, ki bi ga določali dve skrajnosti: verodostojno nanašanje na splošno sprejeta dejstva iz stvarnega sveta na eni strani (kar ustreza realistični reprezentaciji) ter odklon od konvencij verjetnosti ter nujnosti na drugi strani (kar ustreza fantastični 
reprezentaciji). Večina mladinskih proznih žanrov oziroma besedil pa bi se, kot že večkrat poudarjeno, umeščalo v sredino žanra, kot preplet poskusov posnemanja dejanskega sveta in namenskih odklonov od obče veljavnih predstav o njem. Uporaben koncept pri tovrstni spektralni razvrstitvi se zdi v naratologiji že deloma uveljavljen koncept možnih svetov, ki sta ga v preučevanje mladinske književnosti uvedla Mark J. P. Wolf in Maria Nikolajeva.

\section{Teorija možnih svetov v literarnih študijah}

Koncept možnih svetov je $\mathrm{v}$ lingvistiki in filozofiji utemeljen na modalnostih, tj. ne/verjetnosti, nujnosti, željenosti itd. (Wolf 17-20). Marie-Laure Ryan in Alice Bell pišeta, da se v filozofiji koncept možnih svetov osredinja na razmerje med dejanskim svetom, v katerem se fizično nahajamo, in možnimi svetovi, ki jih ustvarja človeška zavest, domišljija. Za razlikovanje med dejanskim svetom in možnimi svetovi modalna logika uporablja koncept dostopnosti, pri čemer (upoštevajoč, da je dejanski svet obenem tudi možni) kot nujno označujemo prepozicijo, ki velja v vseh svetovih, kot možno tisto, ki velja $\mathrm{v}$ nekaterih svetovih, in kot nemogočo tisto, ki ni veljavna v nobenem od svetov. Marie-Laure Ryan in Alice Bell menita, da sta filozofski in naratološki koncept možnih svetov težko združljiva. Prvi se namreč nanaša na prepozicije oziroma izjave, stavke, ki so konsistentni in dovršeni, drugi pa na narativne konstrukte, ki so nedovršeni pripovedni svetovi. Kljub temu so v sedemdesetih letih preteklega stoletja filozofske ideje semantike možnih svetov začele prodirati v literarne študije in razvijati nove poglede na razmerje med literarnimi teksti in resničnostjo. Thomas G. Pavel je po mnenju Marie-Laure Ryan in Alice Bell prvi literarni teoretik, ki je pravilno doumel potencial možnih svetov za teorijo pripovednosti. S pomočjo teorije možnih svetov je v članku "Possible Worlds in Literary Semantics" (1975) in poznejši knjigi Fictional Worlds (1986) uveljavil tezo o resničnosti propozicij, ki jih postavljajo fikcijski teksti, ne da bi omejevali ta besedila na reprezentacijo resničnega, stvarnega zunajtekstualnega sveta. Literarni tekst za bralca ustvari fikcijski možni univerzum oziroma sistem možnih svetov. Ta uveljavi svoja pravila in posledično določi svoj horizont možnega. Da bi se lahko potopil v ta svet, mora bralec privzeti novo ontološko perspektivo, drugačno od tiste $\mathrm{v}$ vsakdanjem življenju, in z njo tudi nov model tega, kaj obstaja dejansko in kaj zgolj kot možnost, to pa je bistvo avtonomije literarnih 
svetov. Skrajna pozicija naivnega realizma bi kategorizirala izjave v fikcijskem svetu glede na to, če so resnične ali lažne glede na predstavljanje dejanskega sveta. Literarna semantika, osnovana na konceptu možnih svetov, pa pojmuje propozicije, ki izvirajo iz fikcijskega sveta, kot konstitutivne za ta svet in posledično kot avtomatično resnične znotraj njega. Obenem pa Pavel tudi svari pred prestrogim razmejevanjem med fikcijskim in dejanskim svetom, saj bi taka razmejitev onemogočila fikciji vpoglede $\mathrm{v}$ naš svet in odvzela literaturi vsako eksistencialno, etično in politično vrednost (Bell in Ryan 9). Nov pogled na razmerje med fikcijskimi in možnimi svetovi je vpeljal Umberto Eco, in sicer tako, da je nadgradil Pavlovo teorijo o literarnem tekstu kot sistemu možnih svetov. Možne svetove po Ecu pogojujejo tri paradigme vstopa v tekst. Kadar jih vzpostavlja avtor, gre za možne svetove, ki se vzpostavljajo $v$ fabuli. Ta tip je najbližje dejanskemu svetu znotraj literarnega univerzuma. Drugi tip se nanaša na modalna stanja likov v pripovedi. Tretji tip pa zadeva možne svetove, ki jih s svojimi predvidevanji, željami v procesu bralskih konkretizacij ustvarja bralec (Eco 235).

Možni svetovi se $\mathrm{v}$ literarni naratologiji najpogosteje razvrščajo glede na njihovo razmerje do dejanskega sveta. $V$ nadaljevanju bom primerjala klasifikacijo, ki jo je $\mathrm{v}$ študiji Building Imaginary Worlds: The Theory and History of Subcreation leta 2012 objavil Mark J. P. Wolf ter razpravo Marije Nikolajeve v prvem poglavju njene študije Reading for Learning: Cognitive Approaches to Children's Literature (2014). Najbolj intenzivno se zdi nanašanje na dejanski svet Marku J. P. Wolfu v avtobiografiji, Marii Nikolajevi pa v pripovedih o vsakdanu otroka in mladostnika. Pri tem pa ni nujno, da vse specifike v literaturi opisanega resničnega sveta kot take prepozna tudi bralec, še zlasti če je med besedilom in bralcem časovna ali kulturna razlika (Nikolajeva, Reading 37). Manj kot v avtobiografiji je nanašanje na dejanski svet prisotno v biografiji in zgodovinski fikciji, saj ta dva žanra prepletata znano z neznanim, dokazano z izmišljenim (Wolf 27). Nikolajeva med pripovedi, ki jih bralci ne povezujejo z dejanskim svetom, umešča tudi nekatera starejša besedila, ki so v času svojega nastanka veljala za realistična. Meni celo, da je pri neizkušenih bralcih mogoče, da ne ločijo med zgodovinskim in fantazijskim prizoriščem. Poleg tega poudarja, da je v primerjavi z literaturo za odrasle v mladinski literaturi oznaka realizma močno razširjena, zajame namreč tudi nekatera besedila, ki so v literaturi za odrasle umeščene v trivialno, žanrsko literaturo. Kot primere te vrste med drugim navaja detektivke, ljubezenske in športne zgodbe, zgodbe, ki ubesedujejo lov na zaklad. Poosebljene živali, 
igrače in predmete Nikolajeva umešča med nepričakovane oziroma neverjetne pripovedne elemente sicer verjetnih oziroma realističnih literarnih reprezentacij dejanskega sveta. Živalske zgodbe se pojavljajo izključno v otroški literaturi, kot bi pisci verjeli, da je otroško dojemanje sveta še dovolj fleksibilno, da sprejme tudi človeške lastnosti živalskih likov, igrač in predmetov. Nekoliko drugače je z zgodbami o grozljivih bitjih, kot so duhovi, zombiji, vampirji v žanrih gotske in grozljive zgodbe. To vrsto besedil Nikolajeva opredeli tudi kot mladinski oziroma najstniški magični realizem ter jo umesti v bližino koncepta fantastičnega, kot ga razume Todorov, tj. besedil, ki jih zaznamuje bralčevo oklevanje med vero in nejevero v čudežni izvor dogodkov. Najdlje od dejanskega sveta Nikolajeva umesti fantastične pripovedi, ki bralca preko protagonistovega potovanja odpeljejo v neverjetne svetove (Nikolajeva, Reading 35-42). Wolf posveti ključni del svoje študije t. i. sekundarnim svetovom, ki se od konvencionalnih predstav o dejanskem svetu oddaljujejo preko štirih ravni invencije (glej zgoraj). Ko (umetniško) potujujejo splošno sprejete predstave o dejanskem svetu, sekundarni svetovi dejanski svet interpretirajo. Da je sekundarni svet za bralca verjeten, potrebuje invencijo, celovitost in konsistenco, bralec pa mora za ustrezno konkretizacijo sekundarnega sveta razviti t. i. "sekundarno vero" oziroma (po Pavlu) privzeti novo ontološko perspektivo, saj so v sekundarnem svetu razmerja med možnim, obstoječim in nemogočim drugačna kot $\mathrm{v}$ svetu, $\mathrm{v}$ katerem se nahaja bralec (Wolf 39). Tako v sekundarnih, izmišljenih svetovih odkloni od splošno sprejetih konvencij poudarjajo zavest o arbitrarnosti naših predstav o resničnosti. Zato Wolf in Nikolajeva zavračata večvrednost realizma nasproti fantastiki in problematizira stališče, da so fantastični svetovi evazorični, da je torej njihov temeljni namen omogočanje domišljijskega pobega iz stvarnosti. Nikolajeva s poglobljeno interpretacijo treh mladinskih literarnih del dokaže, da lahko bralci tudi z branjem nemimetičnih oziroma nemogočih svetov pridobijo uporabno družbeno znanje o človeški izkušnji (Nikolajeva, Reading 49-73). 


\section{Poskus oblikovanja spektra slovenskih mladinskih pripovedi $v$ razponu med posnemanjem dejanskega sveta in ustvarjanjem neverjetnih svetov}

\begin{tabular}{|c|}
\hline POSNEMANJE DEJANSKEGA SVETA \\
\hline 1. SPOMINSKA PROZA OZIROMA AVTOBIOGRAFIJE \\
2. BIOGRAFIJE \\
\hline 3. PROBLEMSKA BESEDILA \\
\hline 4. PRIPOVEDI O VSAKDANJIH DOŽIVETJIH OTROK/MLADIH \\
\hline 5. AVANTURISTIČNE, LJUBEZENSKE, ZGODOVINSKE, \\
DETEKTIVSKE IDR. PRIPOVEDI \\
6. FANTASTIČNE PRIPOVEDI \\
\hline 7. BAJKE, PRIPOVEDKE, PRAVLJICE, BASNI \\
8. NONSENSNE PRIPOVEDI \\
\hline USTVARJANJE NEVERJETNIH SVETOV
\end{tabular}

Ob zgornji klasifikaciji je potrebno poudariti dvoje. Prvič, oba skrajna pola sta konstrukta. Dosledno literarno posnemanje dejanskega sveta je nemogoče tako zaradi arbitrarnega odnosa med stvarnostjo in jezikom kot tudi zaradi kompleksne narave resničnosti, ki jo posameznik, torej tudi avtor/ica in bralec/ka, dojema parcialno, omejeno s prostorom, časom in lastno telesnostjo. Prav tako je ustvarjanje neverjetnih svetov nemogoče brez nanašanja na stvarnost. Večina mladinskih tekstov torej kombinira poskuse verodostojnega posnemanja realnosti in domišljijskega preoblikovanja slednje. Drugič, kot vsaka klasifikacija je tudi zgoraj navedena nepopolna, saj formulaični prikaz proznih žanrov ne upošteva hibridov in prečenj. Poznamo na primer hibride med (avto)biografijo in pravljico, spoj spominske in avanturistične, spominske in problemske proze, problemskega besedila in pravljice. Namen zgornje klasifikacije je predvsem ponuditi razmislek o možnosti preseganja binarizma realizem/fantastika in opredeljevanju mladinskih proznih besedil $\mathrm{v}$ domeni spektra med posnemanjem predstav o dejanskem svetu in izmišljanjem alternativ le-temu. Po definiciji Marka J. P. Wolfa je reprezentacija v avtobiografijah oziroma spominski prozi najbolj vpeta $\mathrm{v}$ podatke iz dejanskega sveta. Paradigmatski vzorec slovenske mladinske avtobiografske spominske proze so vzpostavili Ivan Cankar (Moje življenje), Prežihov Voranc 
(Solzice), Mira Mihelič (Pridi, mili moj Ariel). Kasneje so ga nadgradili in prevrednotili France Bevk, Kajetan Kovič, Kristina Brenk, Berta Golob, Tone Partljič, Franjo Frančič in drugi. Podatki o kulturnem, zgodovinskem in prostorskem kontekstu so sicer v večji ali manjši meri prisotni v vseh besedilih, vendar gre v spominski prozi za posebej zanimiva dejstva, saj ta odslikavajo dejanski pretekli, izginuli svet. Spominska proza je torej s tega gledišča - kot pričevanje, zgodovinski vir, vtkan v fikcijo - zanimiv tudi iz etnološkega, zgodovinskega in sociološkega stališča. Etnološko slovenska proza prikazuje najpogosteje kmečki prostor in kulturo, drobce takih življenjskih zgodb najdemo v Drobnih zgodbah Berte Golob in Prvi domovini Kristine Brenk. Popise meščanskih oziroma nekoliko premožnejših družin najdemo deloma v knjigi Mire Mihelič Pridi, mili moj Ariel in Špelce, kjer Polonca Kovač prepleta spominsko, informativno in doživljajsko prozo. Zelo pogosti v tem žanru so opisi konkretnih primerov revščine ter družbenih neenakosti in krivic. V dokumentarno beleženje preteklih družbenih praks sodijo tudi prikazi ljudskih izročil in verovanj (Haramija, "Slovenska« 62). Najnovejše primere proze z elementi avtobiografije najdemo pri Suzani Tratnik, Žigi X. Gombaču in Branetu Mozetiču: njihova dela so pogosto umeščena v mestno ali predmestno okolje. Biografije so po Wolfu bližje dejanskim kot neverjetnim svetovom. Vendar pa se v številnih sodobnih biografijah, namenjenih mladim (npr. Mojiceja Podgoršek, Ivan Sivec, Primož Suhodolčan) bolj kot predstavljanje (prej dokumentiranih) dejstev iz življenja znamenite osebe soočamo $s$ besedilom, ki služi oblikovanju kulturne pripadnosti preko spoznavanja "nacionalnih junakov" in komercializaciji. Uspeh športnikov je v slikanicah o Tini Maze in Goranu Dragiću prikazan kot pravljica, ki naj mlade bralce motivira in navdihuje. Tretja kategorija proze tematizira probleme in tabuje. Zato se ta tip besedil včasih bliža naturalistični fikciji, ki si prizadeva razkrivati protislovja, napake in nasploh "gnojne rane« družbe, vendar najpogosteje s subjektivne, prvoosebne perspektive, (npr. Ida Mlakar Črnič, Suzana Tratnik, Cvetka Bevc, Marjana Mojškrič, Janja Vidmar, Neli Kodrič Filipić idr.). Ker so družbeni tabuji v problemskih besedilih mnogo lažje prepoznavni kot $\mathrm{v}$ besedilih, ki resničnost izrazito estetizirajo in potujujejo, so prva mnogo pogosteje sprejeta $\mathrm{z}$ odporom in zanikanjem (Saksida, "Nekaj« 61).

Produkcija problemskih besedil kot tudi znanstveno in strokovno preučevanje le-teh je na Slovenskem $v$ zadnjih desetletjih $v$ porastu, tabu teme pa se uveljavljajo tudi $\mathrm{v}$ slikanicah oziroma $\mathrm{v}$ besedilih za najmlajše bralce. Četrta kategorija zajema prikaze vsakdanjosti 
mladih. Te, kot smo nakazali zgoraj, dogajanje najpogosteje zgoščajo v sekvenco napetih, nenavadnih in humornih dogodkov (za pregled slovenske mladinske doživljajske proze glej Haramija, »Pregled «). V zadnjih letih humorne in napete opise doživljajev običajnih otrok in mladostnikov pogosto najdemo v delih Nataše Konc Lorenzutti, Andreja Skubica idr. Peta kategorija, tj. različne vrste avanturističnih, ljubezenskih, zgodovinskih, detektivskih in drugih žanrskih pripovedi so v zgornji tabeli umeščene na sredo spektra med posnemanjem dejanskega in izmišljanjem neverjetnega. Čeprav načeloma ta vrsta besedil ne podaja nadnaravnega dogajanja in prostora, pa v zgoščanju nenavadnih dogodkov in intenziviranju pripovedne napetosti oziroma suspenza prevladuje predvsem želja po ustvarjanju zanimive zgodbe in manj po posnemanju dejanskega sveta. Poleg tega pa številne sodobne avanturistične in zgodovinske pripovedi $\mathrm{v}$ želji po fasciniranju mladega bralca $v$ tekst integrirajo tudi elemente fantastike. Pripovedi, v katerih so protagonisti personificirane živali, se po mojem mnenju umeščajo v kategorije pravljic, pripovedk in fantastičnih pripovedi, saj je svet, v katerem se živali obnašajo kot ljudje, bližje neverjetnemu kot dejanskemu. O fantastičnih pripovedih, ki ob posnetku dejanskega vzpostavljajo tudi različne sekundarne (po Wolfu) možne in neverjetne svetove, so med drugimi pisali Metka Simončič, Marjana Kobe, Metka Kordigel, Jakob Jaša Kenda, Gregor Artnik in drugi. Menim, da so nonsensne pripovedi tiste, ki se znotraj zgornjega spektra najbolj oddaljujejo od posnemanja dejanskega sveta. Ta prozni žanr je v sodobni slovenski mladinski literaturi najizraziteje razvil Peter Svetina. Subverzija obče veljavne resnice se pri Svetinovem nonsensu po eni strani dogaja "brez reza" oziroma tako, da se verjetno in nenavadno oziroma neverjetno zlivata (glej npr. Sosed pod stropom, Uho sveta). Odkloni od družbeno sprejetih verzij resničnosti so v Svetinovi prozi najpogosteje utelešeni v protagonistih in variirajo od nenavadnega (lik, ki si noče striči nohtov; udeleženec v kolesarskem tekmovanju, ki se odreče zmagi) do neverjetnega (profesor, ki leti; pekovka, ki občasno prebiva v krofih), vendar so njihova čudaštva in neverjetne lastnosti integrirane v pripoved kot nekaj pozitivnega in pomenskega. Redkeje, najizraziteje v zbirki Uho sveta in "romančku" Modri Portugalec pa Svetina v pripoved uvede ontološke odklone, in sicer tako, da umetniško potuji parametre fizičnih in časovno-prostorskih zakonov. Prav ta potujena realnost $\mathrm{v}$ Svetinovi prozi spodbuja bralce, da razmišljamo o vrednotah in praksah, ki jih v dejanskem svetu nekritično sprejemamo kot realne, dane, naravne. Družbena angažiranost nonsensa pa je dostopna le zelo predanim bralcem oziroma tistim, ki so priprav- 
ljeni razmisliti, ovrednotiti in morda tudi posvojiti novo percepcijo resničnosti, ki jo ponuja takšno besedilo.

Tudi v mladinski prozi je veristično literarno posnemanje izmuzljivo zaradi arbitrarne narave odnosa med jezikom in stvarnostjo kot tudi zaradi kompleksnosti resničnosti, ki jo je težko zvesti na obče veljavno resnico. Zato je delitev na realistično prozo kot mimetično in empirično preverljivo reprezentacijo stvarnosti ter fantastiko kot njenim nasprotjem (ki mu je neutemeljeno večkrat pripisana manjša spoznavna vrednost) problematično. $V$ članku sem dokazovala, da večina slovenskih mladinskih proznih del prepleta predstavljanje podatkov, ki se verodostojno nanašajo na dejanski svet, $\mathrm{z}$ različnimi prevpraševanji uveljavljenih predstav o stvarnosti, in sicer prvenstveno preko vživljanja $\mathrm{v}$ otroško oziroma mladostniško preoblikovanje le teh s pomočjo igre, domišljije, humorja in nonsensa.

VIRI

Bevc, Cvetka. Stekleni plameni. Maribor: Pivec, 2020.

Cankar, Ivan. Moje življenje. Ljubljana: Mladinska knjiga, 1978.

Golob, Berta. Skrinja iz babičine bale. Ljubljana: Borec, 1983

Golob, Berta. Drobne zgodbe. Ljubljana: Mladinska knjiga, 1986.

Gombač, Žiga. Lumpsterji. Dob pri Domžalah: Miš, 2020.

Karlovšek, Igor. Pobeg. Dob pri Domžalah: Miš, 2020.

Kodrič Filipić, Neli. Punčka in velikan. Ljubljana: Mladinska knjiga, 2009.

Konc Lorenzutti, Nataša. Nisem smrklja. Ljubljana: Mladinska knjiga, 2017.

Kovač, Polonca. Kaja in njena družina. Ljubljana: Mladinska knjiga, 2013.

Kovač, Polonca. Špelce. Ljubljana: Borec, 1983.

Milčinski, Fran. Ptički brez gnezda. Ljubljana: Karantanija, 1991.

Mlakar Črnič, Ida. Tu blizu živi deklica. Ljubljana: KUD Sodobnost International, 2019.

Moškrič, Marjana. Ledene magnolije. Ljubljana: Cankarjeva založba, 2002.

Podgoršek, Mojiceja. Veliki Slovenci. Domžale: Epistola, 2018.

Prežihov, Voranc. Solzice. Ljubljana: Mladinska knjiga, 2011.

Sivec, Ivan. Resnica o Prešernu. Dob pri Domžalah: Miš, 2017.

Skubic, E. Andrej. Ne bi smel odpreti tistih vrat. Ljubljana: Mladinska knjiga, 2018.

Sokolov, Cvetka. Kot noč in dan. Dob pri Domžalah: Miš, 2020.

Sokolov, Cvetka. Vsak s svojega planeta. Dob pri Domžalah: Miš, 2018.

Pregl, Slavko. Geniji v kratkih hlačah. Ljubljana: Mladinska knjiga, 1983.

Suhodolčan, Primož. Košarkar naj bo! Ljubljana: Karantanija, 1994.

Suhodolčan, Primož. Tina in medvedja moč: Tina Maze, resnična pravljica. Ljubljana: DZS, 2019.

Suhodolčan, Primož. Goran, legenda o zmaju: Goran Dragić, resnična pravljica. Ljubljana: DZS, 2017.

Svetina, Peter. Sosed pod stropom. Ljubljana: KUD Sodobnost International, 2016.

Svetina, Peter. Uho sveta. Dob pri Domžalah: Miš, 2017.

Svetina, Peter. Kako je gospod Feliks tekmoval s kolesom. Dob pri Domžalah: Miš, 2017. 
Svetina, Peter. Modri Portugalec: romanček. Ljubljana: KUD Sodobnost International, 2021.

Vidmar, Janja. Debeluška. Ljubljana: Mladinska knjiga, 1999.

Vidmar, Janja. Princeska z napako. Ljubljana: DZS, 2002.

Vidmar, Janja. Fantje iz gline. Ljubljana: Mladinska knjiga, 2005.

\section{LITERATURA}

Artnik, Gregor. »Mladinska fantastična pripoved in njena umestitev v koncept sodobne slovenske mladinske fantastične proze«. Revija za elementarno izobraževanje 5.1 (2012): 23-36.

Bahtin, Mihail Mihajlovič. Ustvarjanje Françoisa Rabelaisa in ljudska kultura srednjega veka in renesanse. Ljubljana: LUD Literatura, 2008.

Bell, Alice, in Ryan, Marie-Laure. »Introduction: Possible Worlds Theory Revisited«. Possible Worlds Theory and Contemporary Narratology. Ur. Alice Bell in MarieLaure Ryan. Lincoln, NE; London: University of Nebraska Press, 2019.

Blažić, Milena Mileva. "Slovenska realistična in fantastična pripoved pri pouku književnosti v osnovni šoli«. Slovenski roman. Simpozij Obdobja 21. Ur. Miran Hladnik in Gregor Kocijan. Ljubljana: Filozofska fakulteta, Center za slovenščino kot drugi/ tuji jezik, 2002.

Butler, Catherine. »Modern Children's Fantasy«. The Cambridge Companion to Fantasy Literature. Ur. Edward James in Farah Mendlesohn. Cambridge: Cambridge University Press, 2012. 224-235.

Coats, Karen. Bloomsbury introduction to children's and young adult literature. London: Bloomsbury Academic, 2018.

Dalley, Hamish. "Postcolonialism and the Historical Novel: Epistemologies of Contemporary Realism «. Cambridge Journal of Postcolonial Literary Inquiry 1.1 (2014): $51-67$.

Eco, Umberto. The Role of the Reader: Explorations in the Semiotics of Texts. Bloomington, IN: Indiana University Press, 1984.

Jakobson, Roman. "On realism in Art". Language in Literature. Ur. Krystyna Pomorska in Stephen Rudy. Cambridge, MA; London: Harvard University Press, 1987. $19-27$.

Haramija, Dragica. »Tipologija slovenske mladinske realistične avanturistične proze«. Jezik in slovstvo 45.4 (2000): 133-141.

Haramija, Dragica. "Pregled sodobne slovenske mladinske proze«. Jezik in slovstvo 50.3/4 (2005): 27-36.

Haramija, Dragica. "Slovenska mladinska realistična kratka pripovedna proza po letu 1950«. Slovenska kratka pripovedna proza. Simpozij Obdobja 23. Ur. Irena Novak Popov. Ljubljana: Filozofska fakulteta, Center za slovenščino kot drugi/tuji jezik, 2006. 59-70.

Hume, Kathryn. Fantasy and mimesis. New York, NY; London: Methuen, 1984.

Juvan, Marko. »Fikcija in zakoni«. Primerjalna književnost 26.1 (2003): 1-20.

Kenda, Jakob Jaša. »Novejše teorije fantastične literature«. Literatura 10.83/84 (1998): 161-189.

Kenda, Jakob Jaša. "Strokovna in znanstvena recepcija sodobne fantazijske literature«. Otrok in knjiga 33.65 (2006): 5-14.

Kobe, Marjana. "Otroški bidermajer na Slovenskem«. Zbornik ob sedemdesetletnici Janka Kosa. Ur. Darko Dolinar in Tomo Virk. Posebna številka revije Primerjalna književnost 24.3 (2001): 115-127. 
Kobe, Marjana. Pogledi na mladinsko književnost. Ljubljana: Mladinska knjiga, 1987.

Kobe, Marjana. »Trije modeli realistične proze v sodobni slovenski mladinski književnostiผ. Jezik in slovstvo 32. 4 (1987): 89-97.

Koron, Alenka. »Fikcija, fakti in resnica v avtobiografiji«. Avtobiografski diskurz: teorija in praksa avtobiografije $v$ literarni vedi, humanistiki in družboslovju. Ur. Koron Alenka in Leben Andrej. Ljubljana: ZRC SAZU, 2011. 35-49.

Kordigel Aberšek, Metka. Didaktika mladinske književnosti. Ljubljana: Zavod Republike Slovenije za šolstvo, 2008.

M. K. »Košarkar naj bo - zgodba, ki so jo pisali resnični junaki, zdaj tudi v filmu«. RTV SLO. 31. 7. 2017. Splet. 1. 6. 2021. <https://www.rtvslo.si/kultura/novice/kosarkar-naj-bo-zgodba-ki-so-jo-pisali-resnicni-junaki-zdaj-tudi-v-filmu/428941>

Nikolajeva, Maria. Reading for Learning: Cognitive approaches to children's literature. Philadelphia, PA; Amsterdam: John Benjamins Publishing Company, 2014.

Nikolajeva, Maria. Power, Voice and Subjectivity in Literature for Young Readers. New York, NY; London: Routledge, 2010.

Pavel, Thomas. »'Possible Worlds' in Literary Semantics". Journal of Aesthetics and Art Criticism 34.2 (1975): 165-176.

Pavel, Thomas. Fictional Worlds. Cambridge, MA: Harvard University Press, 1986.

Ryan, Marie-Laure. Possible Worlds, Artificial Intelligence, and Narrative Theory. Bloomington, IN: Indiana University Press, 1991.

Saksida, Igor. "Opredelitve in predstavitve otroštva v sodobni slovenski mladinski književnosti: tipološki oris«. Posebna izdaja revije Otrok in knjiga 26 (1999): 7-17.

Saksida, Igor. „Mladinska književnost«. Slovenska književnost III. Ur. Tine Logar idr. Ljubljana: DZS, 2001. 403-468.

Saksida, Igor. " Nekaj nezaslišanega): tabu teme v slovenski mladinski poeziji od ljudske pesmi do sodobnosti«. Jezik in slovstvo 47.1/2 (2001/2): 5-16.

Simončič, Metka. "Fantastična pripoved na Slovenskem in v zapadni Evropi«. Dialogi 1.5 (1965): 249-252.

Todorov, Tzvetan. Introduction à la littérature fantastique. Paris: Editions du Seuil, 1970.

Todorov, Tzvetan. The fantastic: a structural approach to a literary genre. Cleveland, $\mathrm{OH}$ : The Press of Case Western Reserve University, 1973.

Tratnik, Suzana. Ime mi je Damjan. Ljubljana: ŠKUC, 2001.

Virk, Tomo. Moderne metode literarne vede in njihove fllozofsko teoretske osnove: metodologija 1. Ljubljana: Znanstvena založba Filozofske fakultete, 2008.

Višček, Sabina. "Stališča učiteljev do problemskih besedil pri pouku književnosti«. Revija za elementarno izobraževanje 7.2 (2014): 63-80.

Wolf, Mark J. P. Building Imaginary Worlds: The Theory and History of Subcreation. New York, NY: Routledge, 2012. 


\section{Slovenian Children's Prose between the Imitation of the Actual and the Creation of Possible Worlds}

Keywords: Slovenian literature / children's literature / realism / fantasy / possible worlds theory

This article presents the distinction between realism and fantasy in children's literature which stems from two different modes of representing the world. Realistic narration usually corresponds to the conventional notions of what is possible or plausible in the knowable, actual world, while fantasy problematizes certain generally accepted notions of (social) reality by creating alternative worlds. I suggest that most children's prose interweaves both representational principles. In realistic prose, the adult author uses imagination, rebellion, humor and nonsense to identify with the young reader and thus subverts the attempts of the adult authoritative perspective to acquire objective and irrefutable validity. Similarly, fantasy cannot exist without references to the empirically veritable actual world. Thus, my suggestion is to modify the existing binarism into a specter that draws on the concepts of modal realism and possible worlds. The genres that gravitate towards one pole of the specter appear primarily to imitate the actual world, e.g., autobiography, memoirs and historical prose. The genres that incline toward the other pole challenge our knowledge by creating alternative worlds, e.g., fantasy, fairy-tale, nonsense.

1.01 Izvirni znanstveni članek / Original scientific article

UDK 82.0-93

821.163.6.09-93

DOI: https://doi.org/10.3986/pkn.v44.i3.06 